\title{
Ultrasound Assisted Extraction and Response Surface Methodology and Artificial Neural Network Optimization of Pectin From Orange Peel
}

Ketema Beyecha Hundie ( $\square$ ambobara2012@gmail.com )

School of Chemical Engineering, Jimma institute of Technology, Jimma University, Jimma, Ethiopia

Research

Keywords: Pectin, Extraction, Response surface Method and Artificial neural network Model

Posted Date: October 29th, 2020

DOI: https://doi.org/10.21203/rs.3.rs-97714/v1

License: (c) (1) This work is licensed under a Creative Commons Attribution 4.0 International License.

Read Full License 


\title{
Ultrasound Assisted Extraction and Response Surface Methodology and Artificial Neural Network Optimization of Pectin from Orange Peel
}

\author{
Corresponding author; Ketema Beyecha Hundie \\ School of Chemical Engineering, Jimma institute of Technology, Jimma \\ University, Jimma, Ethiopia
}

Corresponding author email: ktmbych2001@gmail.com; ambobara2012@gmail.com

$$
\text { Tel: }+25191355744 ; 0942637868
$$

\begin{abstract}
The objective of study was ultrasound-assisted extraction of pectin from orange peel using response surface method and artificial neural network technique. The following findings are absorbed from the effects of extraction parameters and technique used. The pH solution was highly significant compared to ultrasound power. As well as interaction between ultrasound and $\mathrm{pH}$ were found to be strongly influenced the extraction yield of pectin. The optimal parameters for extraction were irradiation time of 22.5min, $\mathrm{pH}$ of 1.5 , and ultrasound power of $155 \mathrm{~W}$ and liquid-solid ratio 22.5:1 $\mathrm{mL} / \mathrm{g}$.
\end{abstract}

Under these conditions, yield of pectin was $26.87 \%$ experimentally, while 26.74 and $26.93 \%$ of yield were predicted by response surface and artificial neural network model respectively.

\section{Introduction}

Industrial wastes and accumulation generated per year are direct consequence associated with
The extracted pectin was categorized as high methoxyl pectin, since it has $63.13 \%$ degree of esterification, which is above 50\% affirmed by Fourier transform infrared spectroscopy detection.

Both response surface methodology and artificial neural network model prediction was in good agreement with experimental data; however, the prediction of artificial neural network prediction was better than artificial neural network.

Therefore, artificial neural network model is much more accurate in estimating the values of pectin yield and mean square error when compared with the response surface methodology.

Key word; Pectin, Extraction, Response surface Method and Artificial neural network Model.

universe population growth that brings the environmental pollution issues. Food processing industry wastes and agricultural wastes rich in 
reusable materials are used for the bioconversion to value added products like additive product, biofuel and active biochemical materials (Salleh et al., 2011). One of, the largest product in worldwide per year are citrus fruits. Almost about fifty percent quantities of fruits are disposed as a waste by citrus-processing industries (Sharma et al., 2017). Air quality, soil purity and sources of water around citrus processing industry, are directly consequences of problems, generated from these uncontrolled waste of this industry to the environmental (Zema et al., 2018). However, these products (citrus peels) are used in several industries as polymethoxylated flavonoids that are applied as phytochemical, pharmaceuticals, food products (Kim et al., 2004) . Conversion of these wastes to valuable product is considered as an alternate and common practices for recycling of byproduct and environmental management systems ( $\mathrm{Ng}$ et al., 2020).

One of the most source of raw materials largely produced in the worldwide are orange fruits used for extraction of complex compound known as pectin. Pectin is a complex polysaccharide substance contains one third of the mobileular wall of the plants. The larger amount of pectins are located within the middle part of lamella of cell wall and small amount of pectins are between the cell wall of plant (Hamai et. al., 2020). Pectin is used; as gelling, stabilizing and thickening agent jams and jellies confectionery in food as well as in pharmaceutical industry. In industrial level, pectin is divided as: Pectins with a degree of methylation (DM) above 50\% (high methoxyl: HM) and pectins with a degree of methylation (DM) below 50\% (low methoxyl: LM) (Hosseini, Khodaiyan and Yarmand, 2016b). High methoxyl pectin makes gel between $\mathrm{pH}$ of $2-3.5$ in the presence of concentrated co-solutes between 55-75\%; while low methoxyl pectin forms gel in the absence of co-solutes, with the mixture of bivalent ions between $\mathrm{pH}$ of 2-6 (Chan and Choo, 2013). Therefore both types of pectins have dissimilar physical and chemical properties lead to dissimilar applications (Hosseini, Khodaiyan and Yarmand, 2016c). In addition, properties of pectin primarily based on the plant source, the extraction technique chosen for separation as well as purity of final product.

To increase extraction quality as well as the final yield of pectin, the use of an appropriate method is critical point (Berkani et al., 2020).

Extraction of pectins from different plant sources haven been reported in several literatures. Anciently, extraction of pectins from citrus peels have done using hot acidified water that results destroying and make dissimilar its structure and instinctive character and usage of chemicals results wastewater which brings the higher environmental pollution (Hosseini et al., 2019a; Shivamathi et al., 
2019). The use of several advanced techniques( including, enzymes, microwave as well as ultrasound assisted extraction (UAE)) can be used to maximize the final yield and its purity in addition minimizing; time of extraction, energy usage, use of poisonous solvents and concentrated acid for product recovery (Marić et al., 2018). Due to the influence of ultrasound waves to improve the destroying of plant cell wall, increase the rate of mass transporting which bring up the better performance and quality of the product with a shorter time as well as lower consumption of solvents and energy, increased safety of the operators and in environmental problems, ultrasound assisted extraction is considered as alternative method (Hosseini et al., 2019; Marić et al., 2018). In overall, types of extraction variables involved and extraction mechanism will influence the efficiency of the yield.

For successful extraction and optimization, artificial neural network (ANN) and response surface methods (RSM) have been widely used in optimizing various process variables (Tesli et al., 2019; Ye et al., 2014). RSM is widely applied to optimize multivariate system to determine individual as well as combination influences of process parameters. However, RSM based models are only for a restricted range of input parameters and thus, impose a restriction on the use of RSM based models for non- linear behavior (Muthusamy et al., 2019). Artificial neural network (ANN) has wide applications over RSM for non- linear multivariate modeling (Khayet, Cojocaru and Essalhi, 2011) technology that includes different number of layers for selected number of parameters (Ghoreishi, Hedayati and Mousavi, 2016). MATLAB® 2014a was used to build the ANN model with feed forward Multilayer back propagation (FMBP) to predict the response.

Several investigations have been worked to extract pectin from orange peel using traditional as well as current methods. However, extraction of pectin from these peels was not investigated using combinations of current extraction method (UAE) and optimization (RSM and $\mathrm{ANN}^{*}$ ) methods.

Therefore, the goal of this paper was ultrasound assisted extraction and optimization (response surface and artificial neural network) of pectin from orange peel

\section{Materials and methods}

\section{Materials}

The orange peels were collected from juice producer located in Jimma. It was manually cleaned to remove impurity and dried for three days followed by an electric oven dry at $50{ }^{\circ} \mathrm{C}$ until similar weight of the peel achieved. The dried peels were washed, mixed in a mixer grinder and sieved to avoid non-finely particles. The result powder was stored in a dark and dry out place for subsequent requirement. 
Chemicals and solvents:

All analytical grade reagent chemicals and solvents [Citric acid, $\mathrm{HCl}, \mathrm{HS}_{2} \mathrm{O}_{4}$, trifluoro acetic acid, $\mathrm{NaOH}$, ethanol, 2, 2Diphenyl-1-Picrylhydrazyl] were purchased from chemical purchasers.

\section{Experimental Design; Response surface method (RSM) modeling}

Experiment design was developed using Stat Ease Design Expert software version 11.1.0. Based on the design of experiment; central composite deign, the second order polynomial regression model was developed to predict the performance of variables. The extraction parameters selected according to previous literatures as shown in table 1 with coded and actual level.

Table 1: central composite design parameters level for pectin extraction

\begin{tabular}{lllllll}
\hline Parameters & Unit & Minimum & maximum & Levels & & \\
\hline A: Irradiation time & min & 15 & 30 & $10(-1)$ & $25(0)$ & $40(+1)$ \\
B: pH solution & - & 2 & 3 & $2(-1)$ & $2.5(0)$ & $3(+1)$ \\
C: Ultrasound power & $\mathrm{w}$ & 60 & 140 & $60(-1)$ & $100(0)$ & $140(+1)$ \\
D: Liquid-solid ratio & $\mathrm{mL} / \mathrm{g}$ & $15: 1$ & $25: 1$ & $15: 1(-1)$ & $20: 1(0)$ & $25: 1(+1)$
\end{tabular}

The second-order models generated by RSM are often used to determine the critical points and can be written in a general form as (Kleijnen, 2008):

$$
\begin{aligned}
\mathrm{Y}= & \beta_{0} \sum_{\mathrm{i}=1}^{\mathrm{k}} \beta_{\mathrm{i}} \mathrm{X}_{\mathrm{i}}+\sum_{\mathrm{i}=1}^{\mathrm{k}} \beta_{\mathrm{ii}} \mathrm{X}_{\mathrm{i}} \mathrm{X}_{\mathrm{i}}+\sum_{\mathrm{i}=1}^{\mathrm{k}-1} \sum_{\mathrm{j}=\mathrm{i}+1}^{\mathrm{k}} \beta_{\mathrm{ij}} \mathrm{X}_{\mathrm{i}} \mathrm{X}_{\mathrm{j}} \\
& ++\epsilon
\end{aligned}
$$

Where, $\mathrm{Y}, \mathrm{x}_{\mathrm{i}}$ and $\mathrm{x}_{\mathrm{j}}, \beta_{0}, \beta_{\mathrm{i}}, \beta_{\mathrm{i}}, \beta \mathrm{ii}, \mathrm{k}$ and $\epsilon$ are anticipated response, input factors, constant term, linear coefficient, quadratic coefficient, interaction term, number of factors and random error respectively.

Using Eq.(1), if $n$ is the number of repetitions at the cube's center and $\mathrm{R}$ is the total number of run required for four independent variables (irradiation time, $\mathrm{pH}$, Ultrasound power and liquid-solid ratio) is given by Eq.(2):

$$
\mathrm{R}=2^{\mathrm{k}}+(\mathrm{k} * 2)+\mathrm{n}
$$

\section{Artificial neural network (ANN) modeling}

MATLAB® 2014a was used for the formulation of Artificial neural network model using feed forward multilayer network contains three primary layers kwon as input (used hyperbolic tangent sigmoid transfer function), hidden and output layers (used pure-linear transfer function) to anticipate the yield (Nazerian et al., 2018) as indicated in Eq.(4). The developed artificial neural network model constitutes four inputs (irradiation time, $\mathrm{pH}$ solution, ultrasound power and liquid-solid ratio) and one output (pectin). The Marquardt-Levenberg backpropagation (MLBP) algorithm was selected for training. The input and output data detected from the actual values are categorized into different parts; (60\% - eighteen samples) for training (20\% - 
six samples) for testing and (20\% - six samples) for validation.

To find out best training efficiency and reduce the effect of larger values in input and output data, input and output were normalized between -1 and 1 (Muthusamy et al., 2019). The normalized data was forwarded to the artificial neural network model in feed forward multilayer back propagation. The mean square error values between the output neurons and the observational outputs were determined and backward propagated via the network. Then, the individual weights of the neuron, corrected by the algorithm. For cross$F(x)=\operatorname{tansig}(x)=\frac{1-e^{x}}{1+e^{x}}$

\section{Comparison of ANN \& RSM performance:}

The coefficient of determination; $\mathrm{R}^{2}$, Root Mean Squared Error; RMSE, mean average error; MAE, standard error of prediction; SEP, and absolute average deviation; AAD were determined to check the accuracy and predictive ability of ANN and RSM using Eq. (4-9):

$$
\begin{aligned}
& R^{2}=1-\sum_{i=1}^{r}\left\lfloor\frac{\left(y_{p}-y_{e}\right)^{2}}{\left(y_{p}-m\right)^{2}}\right\rfloor \\
& \text { MSE }=1-\frac{1}{r} \sum_{i=1}^{r}\left(y_{p}-y_{e}\right)^{2} \\
& \text { RMSE }=M S E^{1 / 2} \\
& \text { SRP }=\frac{\text { RMSE }}{m} \\
& \text { AAD }=\frac{100}{r} \sum_{i=1}^{r}\left(\frac{y_{e}-y_{p}}{y_{e x p}}\right) \\
& \text { MAE }=\sum_{i=1}^{r}\left\lfloor\frac{y_{e}-y_{p}}{y_{e}}\right\rfloor
\end{aligned}
$$

Where; $r=$ number of run, $y_{p}=$ predicted values from model, $\mathrm{y}_{\mathrm{e}}=$ experimental values and $\mathrm{m}=$ average experimental values validation of parameters, by MATLAB, ANN Tool was developed. After the ANN tool memorizes the data from the training, the cross-validation was applied to prevent over fit of the training. By

Repetition in testing a number of $\mathrm{NN}$, the best number of neurons in the hidden layer was determined when the mean square error (MSE) value of the output reached its minimum value. For determination of the number of neurons required in the hidden layer, addition of the weighted inputs and the related bias are important data towards for nonlinear situation (Cheok et al., 2012; Madadlou et al., 2009).

\section{Extraction of Pectin}

By using previous study as reference with modification and it should also be declared that the degrees of parameters were selected depend on previous study [23, 24] . In all runs, fifteen gram $(15 \mathrm{~g})$ of the peel powder was mixed with $\mathrm{pH}$ of $(1-3)$ citric acid solution in $250 \mathrm{ml}$ flask. It was then sonicated for $(15-30 \mathrm{~min})$, in the range of $(60-120 \mathrm{~W})$, ultrasound power, thereafter the mixture was maintained at temperature of $25^{\circ} \mathrm{C}$ for a certain time and percolated. The percolate carrying pectin was chilled down, for $25 \mathrm{~min}$ and centrifuged at $6500 \mathrm{rpm}$. Ethanol of $96 \%$ was utilized, to precipitate the supernatant and impurities, and allowed for one hour for pectin flotation. The floating result was then classified by filtration process and the result was dried in drier at $50^{\circ} \mathrm{C}$ to remove moisture. The resulting dried pectin was milled to powdered pectin and stored for analysis and its yield was determined using to Eq. (2):

Yield $(\%)=\frac{\text { Amount of dried pectin extracted in gram }(\mathrm{g})}{\text { Amount of sample taken upfor extraction in gram (g) }} * \times 100$ 
Table 2: Independent variables with experimental and response with RSM and ANN prediction

\begin{tabular}{|c|c|c|c|c|c|c|c|}
\hline $\begin{array}{l}\text { Run } \\
\text { Order }\end{array}$ & $\begin{array}{l}\text { Factors } \\
\text { Irradiation } \\
\text { time min }\end{array}$ & $\begin{array}{l}\mathrm{pH} \\
\text { solution }\end{array}$ & $\begin{array}{l}\text { Ultrasound } \\
\text { power (W) }\end{array}$ & $\begin{array}{l}\text { L-S-R } \\
(\mathrm{ml} / \mathrm{g})\end{array}$ & $\begin{array}{l}\text { Actual } \\
\%\end{array}$ & $\begin{array}{l}\text { RSM } \\
\text { Predicted } \\
\% \\
\end{array}$ & $\begin{array}{l}\text { ANN } \\
\text { Predicted } \\
\%\end{array}$ \\
\hline 1 & 30 & 2 & 120 & 30 & 20.01 & 20.10 & 20.4683 \\
\hline 2 & 15 & 3 & 120 & 15 & 9.90 & 9.91 & 9.899 \\
\hline 3 & 22.5 & 2.5 & 85 & 22.5 & 23.23 & 23.17 & 23.21 \\
\hline 4 & 15 & 3 & 50 & 30 & 11.30 & 11.33 & 11.2922 \\
\hline 5 & 30 & 3 & 120 & 30 & 10.30 & 10.30 & 10.301 \\
\hline 6 & 30 & 2 & 50 & 15 & 16.30 & 16.53 & 16.54 \\
\hline 7 & 22.5 & 2.5 & 85 & 7.5 & 16.70 & 16.44 & 16.8996 \\
\hline 8 & 37.5 & 2.5 & 85 & 22.5 & 7.30 & 7.14 & 7.361 \\
\hline 9 & 30 & 2 & 120 & 15 & 22.57 & 22.61 & 22.5638 \\
\hline 10 & 7.5 & 2.5 & 85 & 22.5 & 8.50 & 8.25 & 8.4994 \\
\hline 11 & 22.5 & 2.5 & 15 & 22.5 & 15.80 & 15.52 & 15.783 \\
\hline 12 & 22.5 & 2.5 & 85 & 37.5 & 16.70 & 16.55 & 17.098 \\
\hline 13 & 22.5 & 2.5 & 85 & 22.5 & 23.40 & 23.17 & 23.21 \\
\hline 14 & 30 & 2 & 50 & 30 & 15.01 & 14.94 & 13.5319 \\
\hline 15 & 22.5 & 1.5 & 155 & 22.5 & 26.87 & 26.74 & 26.93 \\
\hline 16 & 22.5 & 3.5 & 85 & 22.5 & 5.75 & 5.47 & 6.1308 \\
\hline 17 & 15 & 2 & 50 & 30 & 15.00 & 15.19 & 14.9644 \\
\hline 18 & 30 & 3 & 50 & 30 & 10.00 & 10.29 & 10.2657 \\
\hline 19 & 15 & 3 & 50 & 15 & 8.31 & 8.70 & 9.5966 \\
\hline 20 & 30 & 3 & 50 & 15 & 8.10 & 8.10 & 8.2907 \\
\hline 21 & 22.5 & 2.5 & 85 & 22.5 & 23.10 & 23.17 & 23.21 \\
\hline 22 & 15 & 2 & 120 & 30 & 20.54 & 20.61 & 21.0478 \\
\hline 23 & 15 & 2 & 120 & 15 & 22.50 & 22.69 & 22.75164 \\
\hline 24 & 22.5 & 2.5 & 85 & 22.5 & 23.00 & 23.17 & 23.21 \\
\hline 25 & 15 & 2 & 50 & 15 & 16.40 & 16.34 & 16.4342 \\
\hline 26 & 30 & 3 & 120 & 15 & 8.88 & 9.04 & 8.938 \\
\hline 27 & 22.5 & 2.5 & 85 & 22.5 & 22.99 & 23.17 & 23.21 \\
\hline 28 & 22.5 & 2.5 & 85 & 22.5 & 23.40 & 23.17 & 23.21 \\
\hline 29 & 22.5 & 2.5 & 85 & 22.5 & 23.23 & 23.17 & 23.21 \\
\hline 30 & 15 & 3 & 120 & 30 & 11.50 & 11.61 & 11.4755 \\
\hline
\end{tabular}

\section{FT-IR spectroscopy}

The produced pectin contents were analyzed by using prinks Elmer spectrum 65 FT-IR technique with the help of IR correlation. The wavenumber region for the analysis was 4000$400 \mathrm{~cm}-1$ (in the mid-infrared range) and IR spectrum was reported by $\%$ transmittance.

\section{Product (Pectin) characterization}

The pectin extracted at the optimum processing conditions (the highest yield) was analyzed by determining the following properties.

\section{Esterification Capacity/degree of esterification}

(EC); - It was calculated using the titrimetric method using potassium hydroxide $(\mathrm{KOH})$, instead of sodium hydroxide. Twenty-five $(25 \mathrm{~g})$ of dried product was moistened with standard ethanol and dissolved in $25 \mathrm{ml}$ of deionized water at forty 
degree Celsius $\left(40{ }^{\circ} \mathrm{C}\right)$. Following full dissolution of product, five pearls of indicators were added to the mixture. The mixture was thereafter volumetrically analyzed with $0.4 \mathrm{M} \mathrm{KOH}$, and the amount of the $\mathrm{KOH}$ solution used for color change was recorded as volume $\left(\mathrm{V}_{1}\right)$. Subsequently, $15 \mathrm{ml}$ of $0.4 \mathrm{M} \mathrm{KOH}$ was added, and the solution was shaken powerfully and allowed to cool down for $10 \mathrm{~min}$. In addition, $15 \mathrm{ml}$ of $0.6 \mathrm{M}$ hydrochloric acid was added and the solution was shaken until the disappearance of pink color. The mixture was volumetrically analyzed with $0.4 \mathrm{M} \mathrm{KOH}$ for the end step and the consumed amount was collected as volume $\left(\mathrm{V}_{2}\right)$ and the esterification capacity was determined using Eq. (11):

$$
\mathrm{EC}(\%)=\frac{\mathrm{v}_{2}}{\mathrm{v}_{1}+\mathrm{v}_{2}} * 100
$$

$\mathrm{EC}=$ esterification capacity of dried product, $\mathrm{V}_{1}$ $=$ initial titer $(\mathrm{ml})$, and $\mathrm{V}_{2}=$ final titer $(\mathrm{ml})$

Equivalent weight (EW) ;- This was calculated as method reported by (Mohamed, 2016); $5 \mathrm{~g}$ of dried product was put in a $250 \mathrm{ml}$ conical flask, and $15 \mathrm{ml}$ ethanol was added. One gram of $\mathrm{NaCl}$ and $100 \mathrm{ml}$ of deionized water were added. Finally, five drops of phenol red indicator was added and volumetrically analyzed with $0.1 \mathrm{M} \mathrm{KOH}$. The end point of volumetric analysis was represented by pink color and the equivalent weight was calculated according to Eq. (12):

$$
\operatorname{EW}(\%)=\frac{\mathrm{m}_{\mathrm{s}} * 1000}{\mathrm{v}_{\mathrm{a}} * K_{n}}
$$

$\mathrm{EW}=$ Molecular mass of dried product, $\mathrm{VA}=$ volume of alkali $(\mathrm{ml})$, and $\mathrm{K}_{\mathrm{en}}=$ normality of potassium.

Methoxyl content (MC);- MC was carried out using the Ranganna's method as reported by (Fakayode and Abobi, 2018). When the neutral solution was accumulated from determination of equivalent weight, $20 \mathrm{ml}$ of $\mathrm{KOH}$ was added. The mixed solution was stirred thoroughly and kept at $25^{\circ} \mathrm{C}$ for $25 \mathrm{~min}$. Then after, $25 \mathrm{~min}, 20 \mathrm{ml}$ of $0.3 \mathrm{M}$ $\mathrm{HCl}$ introduced and volumetric analysis started with $0.1 \mathrm{M} \mathrm{KOH}$. The content of methoxyl was calculated using Eq. (13):

$$
\begin{aligned}
& \mathrm{MC}(\%)=\frac{V_{a} * N_{a} * 3.1}{m_{s}} \\
& \mathrm{MC}=\text { methoxyl content of dried product }
\end{aligned}
$$

Total anhydrouronic acid content (TAAC);This was carried out using the method adopted by Mohamed, (2016) and determined using Eq. (14):

$$
\operatorname{TAAC}(\%)=1.76 * \frac{(\mathrm{a}+\mathrm{b})}{\mathrm{m}_{\mathrm{s}}}
$$

TAAC = total anhydrouronic acid content of dried product $\mathrm{a}=$ volume of $\mathrm{KOH}$ from equivalent weight determination $(\mathrm{ml})$, and $\mathrm{b}=$ volume of $\mathrm{KOH}$ from methoxyl content finding $(\mathrm{ml})$ and $\mathrm{m}_{\mathrm{s}}=$ mass of sample $(\mathrm{g})$

Acetyl value (AV);- This was carried out using the Ranganna's method as reported by (Kliemann et al., 2009); $5 \mathrm{~g}$ of dried product was dissolved in 0.2 $\mathrm{M} \mathrm{KOH}$ solution by stirring and allowed to stand overnight. The contents were diluted to $40 \mathrm{ml}$ with deionized water and an aliquot $(15 \mathrm{ml})$ was located into the distillation equipment. Magnesium sulfatesulfuric acid mixture $(15 \mathrm{ml})$ was also shifted to distillation equipment and distilled. About $100 \mathrm{ml}$ of distillate was collected and the distillate was titrated with $0.4 \mathrm{M} \mathrm{KOH}$ using phenol red indicator. A blank distillation using $15 \mathrm{ml}$ of the Magnesium sulfate- sulfuric acid solution was carried out, and the distillate was volumetrically analyzed. The acetyl content was calculated using Eq. (15):

$$
\operatorname{ACV}(\%)=\frac{\mathrm{V}_{\mathrm{a}} * \mathrm{~N}_{\mathrm{a}} * 4.3}{\mathrm{~m}_{\mathrm{s}}}
$$


$\mathrm{ACV}=$ acetyl value of dried product

\section{Results and discussion}

Validation of RSM model optimization for experimental data analysis

A very good correspondence between the observational and anticipated values for pectin yield was obtained from the check bit plot between the anticipated and the observational values as shown in Fig. 2.The anticipated values and observed values are in reasonable agreement, since there is closeness between the both results for pectin yield. Referencing table 2, the expected optimum pectin yield was $26.74 \%$ at time of 22.5 min, $\mathrm{pH}$ of 1.5 , ultrasound power of $155 \mathrm{~W}$, and liquid-solid ratio of $22.5: 1 \mathrm{~mL} / \mathrm{g}$ using Eq. (10). Under these conditions, the actual value of pectin was $26.87 \%$, which in corresponding with those expected by computation.

The UAE yield of pectin was less than the result reported by, Hosseini et al. (2019), from microwave-assisted extraction $(28.07 \pm 0.67 \%)$ and higher than, , Hosseini et al. (2016) aqueous extraction $(17.95 \pm 0.3 \%)$ in their optimum extraction conditions. The variation could be due to; plant source, the extraction technique taken for separation (Hosseini, Khodaiyan and Yarmand, 2016c). however, the result indicates that the UAE method is an efficient technique since; this it has minimum consumption of time and energy and in addition, that the extracted yield of pectin in this research was better than result achieved by Wikiera et al., (2016) $19.8 \%$ of pectin yield from apple pomace by Endo-xylenes and endo-celluloseassisted method. Shivamathi et al. (2019) has reported the achievement of $8.93 \%$ yield of pectin from custard apple peel at optimized conditions. This implies that the model chosen for anticipation of the pectin yield from orange peel was adequately.

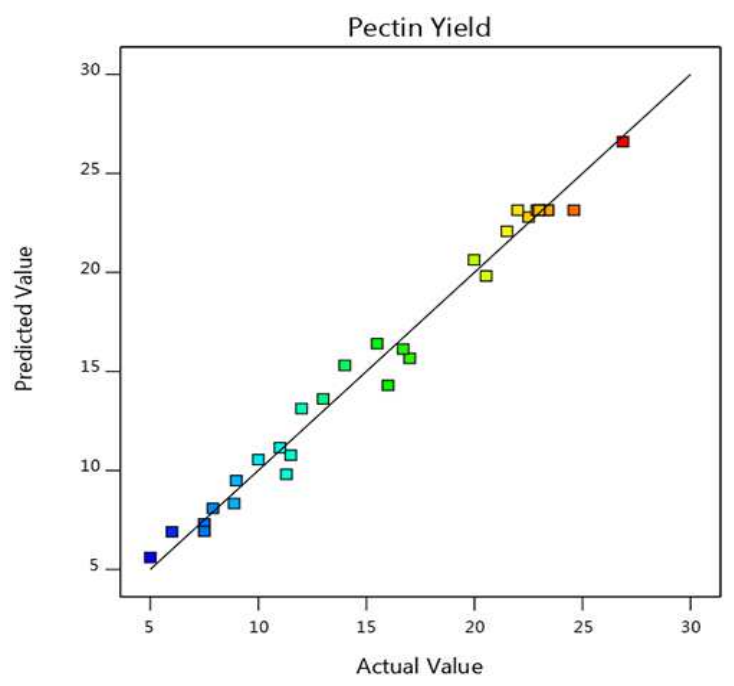

Fig. 1. Experimental value versus RSM expected of pectin yield $(\%)$.

The regression coefficient (interms of coded), variance analysis of the expected model and all colleration coefficients( $R^{2}, R^{2}$ adj and $\mathrm{R}^{2}$ pre) have been used to test the goodness of the model (Zhang et al., 2014) listed in Table 3. The analysis results proved that the relationship between factors and the response of the expected model was well correlated. Residual is the difference between the actual and the fitted value of a model and it is used to predict the adequacy of the model. Small residual mean's; model anticipated is accurate (Samavati, 2013). The F and P-value tested the statistical effluences of all the terms of the model.

The corresponding variables would be more significant if the F-value became higher and the Pvalue became smaller (Zhang et al., 2014). In this study, results showed that, high F-value and $\mathrm{p}$ value of developed model were below 0.05 , which in turn show the fitness of model was strongly significant (Prakash et al., 2013 .The results also proved that, the proposed regression model for pectin yield was satisfactory high with all squared 
$R$ values table3, which exhibited a closeness between the actual and the anticipated values by the model.

TABLE 3: ANOVA for Quadratic model

\begin{tabular}{llllll}
\hline Source & Sum of Squares & DF & Mean Square & F-value & p-value \\
\hline Model & 1160.73 & 14 & 82.91 & 1305.28 & $0.0001^{* * *}$ \\
A-irradiation time & 1.86 & 1 & 1.86 & 29.27 & $0.0001^{* * *}$ \\
B-pH solution & 362.96 & 1 & 362.96 & 5714.31 & $0.0001^{* * *}$ \\
C-Ultrasound power & 48.42 & 1 & 48.42 & 762.26 & $0.0001^{* * *}$ \\
D-L-S-R & 0.0204 & 1 & 0.0204 & 0.3214 & $0.5791^{*}$ \\
AB & 0.6320 & 1 & 0.6320 & 9.95 & $0.0065^{* *}$ \\
AC & 0.0729 & 1 & 0.0729 & 1.15 & $0.3010^{*}$ \\
AD & 0.1936 & 1 & 0.1936 & 3.05 & $0.1013^{*}$ \\
BC & 34.80 & 1 & 34.80 & 547.81 & $0.0001^{* * *}$ \\
BD & 14.29 & 1 & 14.29 & 224.95 & $0.0001^{* * *}$ \\
CD & 0.8556 & 1 & 0.8556 & 13.47 & $0.0023^{* *}$ \\
A $^{2}$ & 414.24 & 1 & 414.24 & 6521.56 & $0.0001^{* * *}$ \\
B $^{2}$ & 91.14 & 1 & 91.14 & 1434.84 & $0.0001^{* * *}$ \\
$C^{2}$ & 22.57 & 1 & 22.57 & 355.40 & $0.0001^{* * *}$ \\
$\mathrm{D}^{2}$ & 77.15 & 1 & 77.15 & 1214.57 & $0.0001^{* * *}$ \\
Residual & 0.9528 & 15 & 0.0635 & & \\
Lack of Fit & 0.7772 & 9 & 0.0864 & 2.95 & $0.1004^{*}$ \\
Pure Error & 0.1755 & 6 & 0.0293 & & \\
Total & 1161.68 & 29 & & & \\
\hline $\mathrm{R}^{2}$ & & & 0.9678 & & \\
AdJ.R ${ }^{2}$ & & & 0.9475 & & \\
Pred. $\mathrm{R}^{2}$ & & & 0.9575 & & \\
Ade Pr. & & & 26.3910 & & \\
Std. Dev. & & & 1.14 & & \\
Mean & & & 15.78 & & \\
C.V. \% & & 7.23 & & \\
\hline & & & & \\
\hline
\end{tabular}

Highly significant; ***, significant; **, not significant; *

The Pred. $\mathrm{R}^{2}$ of 0.9575 is in reasonable estimate with the Adj. $\mathrm{R}^{2}$ of 0.9475 ; i.e. the distinction is much less than 0.2.The adequate precision ratio of 58.439 shows an adequate signal and this model can be used to navigate the design space since, adequate precision is used to find out the signal to noise ratio and a ratio greater than 4 is desirable. Meanwhile, the very small value of coefficient of variation (CV:7.23\%) clearly shown a very strong degree of precision and a great deal 
of reliability of the experimental values (Prakash et al.(2014). The F-value of 2.95 the lack of fit for this estimation shows that, the model is suitable for anticipation of optimum conditions to extract pectin from orange peel using UAE. The proposed quadratic polynomial model is therefore, perfectly suitable for anticipation of the relationship between independent and dependent variables. The dependent and independent variables are related by the following second-order polynomial equation interms of coded terms by applying multiple regression analysis on the experimental data.

\section{Final Equation in Terms of Coded Factors}

Pectin Yield $=+23.17-0.28 \mathrm{~A}-4.36 \mathrm{~B}+1.59 \mathrm{C}+0.03 \mathrm{D}-$ 0.2AB-0.07AC-0.11AD 1.28BC+0.95BD-0.23CD$3.87 \mathrm{~A}^{2}-2.25 \mathrm{~B}^{2}-1.12 \mathrm{C}^{2}-1.67 \mathrm{D}^{2}$

(16)

The importance of the independent variables and their effects could be indicated by the magnitude and sign of the coefficients (Zhao-Hui et al., 2011). It could be seen from table 3 and Eq. (16), all the liner, the quadratic and the interaction coefficients (BC, BD, CD) were statistically significant.

\section{Effect of extraction variables on the pectin yield}

The result in table 3 and Eq. (16) separately showed that all of the applied factors were highly effective on extraction yield of pectin except liquid-solid ratio not significant. Citric acid $\mathrm{pH}$ solution should be considered more than the other factors, since it was the most influential on extraction process. Similarly, the interaction between $\mathrm{pH}$, solution versus ultrasound power and $\mathrm{pH}$ solution versus liquid-solid ratio had a high influence on the yield of extraction. Apart from the liquid-solid ratio and $\mathrm{pH}$ solution, the interaction between $\mathrm{pH}$ and ultrasound power had highly influenced the yield of pectin. The 3D plots were demonstrated below for more exploration in the relationship between response and parameters. At the least $\mathrm{pH}$ solution and highest ultrasound power, the maximum extraction yield was attained. This means, high acidic media, brought the pectin leakage from the plant substance and in consequence, increased the extraction efficiency(Hosseini et al., 2019b and Dranca, 2019). Another efficient variable that had a direct influence on the extraction was ultrasound power. Fig. 3a reveals that ultrasound power was better efficient in the study, enhancing the ultrasound power; the extraction efficiency was also enhanced. This result may relate to the cavitation consequences of ultrasound waves and this cavitation bring up the solvent insight into intercellular substance of plant and thereby upgrades the pectin escapees leads to increase the extraction efficiency (Wikiera et al., 2016).

Irradiation time is one of the important process parameters that affect the yield of pectin significantly compared to L-S-R in this study. Due to creation of the cavitation bubble by ultrasound waves that supports the disruption of plant cell wall to improve the extraction efficiency of pectin and produce swelling and hydrate the plant material, in the initial stage, the extraction efficiency was increased up to $22.5 \mathrm{~min}$ and the reduction was observed above this value (Shivamathi et al., 2019).

Yield of pectin did not highly influenced with liquid-solid ratio compared to other parameters; an observation that was confirmed by the results of the analysis of variance $(p>0.05)$ and Eq. (16). It can be assumed that varying the range of study above a SLR of 1:22.5 g/mL might be lead to a different conclusion regarding the involvement of this working parameter in the cavitation effect occurring in an extraction assisted by ultrasound method and consequently its impact on the efficiency of extraction (Dranca, 2019). 


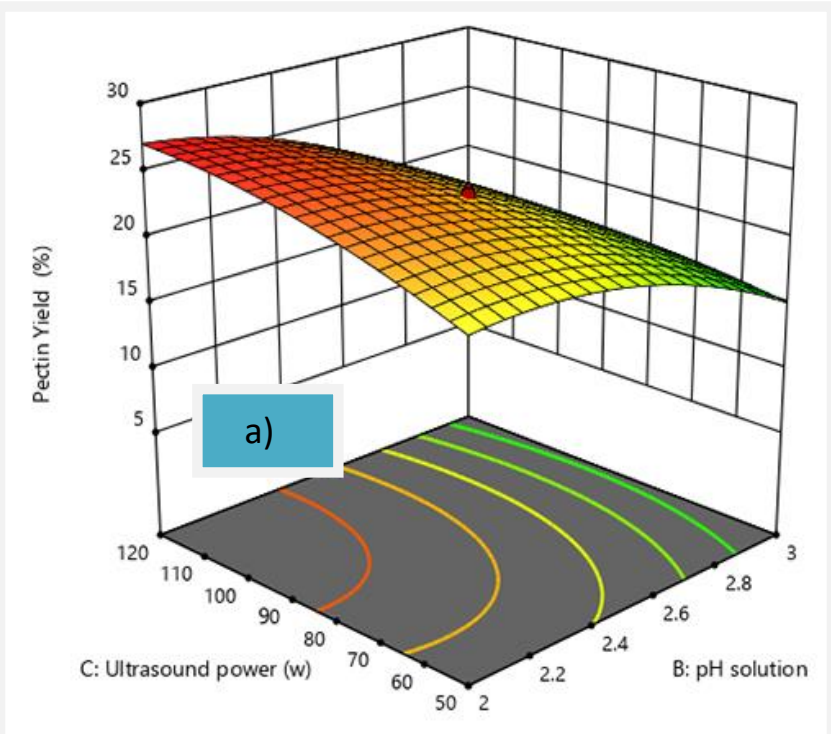

Fig. 2: Ultrasound versus pH (a) and Liquidsolid ratio versus $\mathrm{pH}$ on the yield of pectin (b)

\section{ANN-based modeling}

The ANN anticipation has been carried out successfully using information shown in table 1 . The ANN-based model was done by; choice of the appropriate training algorithm, determination of optimum value of neuron and validation of the model. Eighteen $(80 \%-18)$ samples of the data were used for training, six (20\%-6) samples for testing and six (20\%-6) samples for validation. Using the available actual value, LevenbergMarquardt (LM) ANN fitting tool and TANSIG Transfer Function 4-10-1 (number of input layer, neurons in hidden layer and output layer) model were implemented. Prior training, the network inputs and target were normalized by assigning the maximum (+1) and minimum (-1) levels. Statistical parameters like R; regression coefficient, RMSE; root-mean square error, MAE; mean average error, SEP; standard error of prediction and AAD; absolute average deviation were assumed to

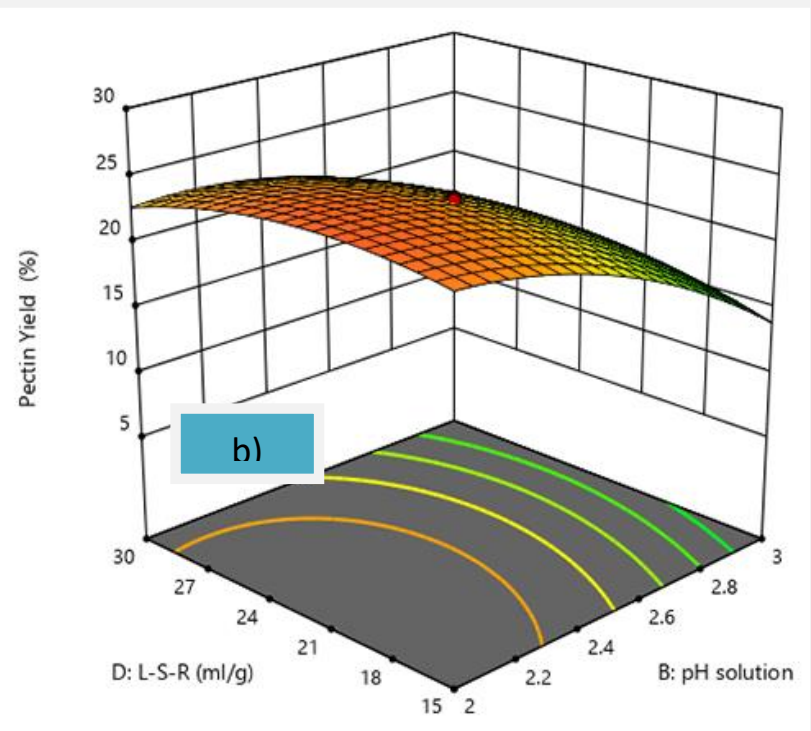

determining the higher predictive power of the model techniques. The statistical values of ANN and RSM models are decided using Eq. (4-9) and shown in table 4.The degree of association or relationship among the parameters in the question was specified by correlation coefficient (R). A unit (1) value of coefficient of correlation implies perfect relationship between variables while zero (0) value is believed to be the absence of linear relationship the parameters. The best solution was chosen based on highest coefficient of correlation and least MSE for training, testing and validation. The correlation coefficients $(\mathrm{R})$ between the actual and the expected values are 0.99943 for training, 0.9863 for testing, 0.99615 for validation and overall correlation was 0.99769 . Therefore, the ANN anticipation for training, validation, and testing is highly substantial and meritorious in terms of correlation. As indicated in Fig. 4 and, the performance value for the final iteration gave a best result. 


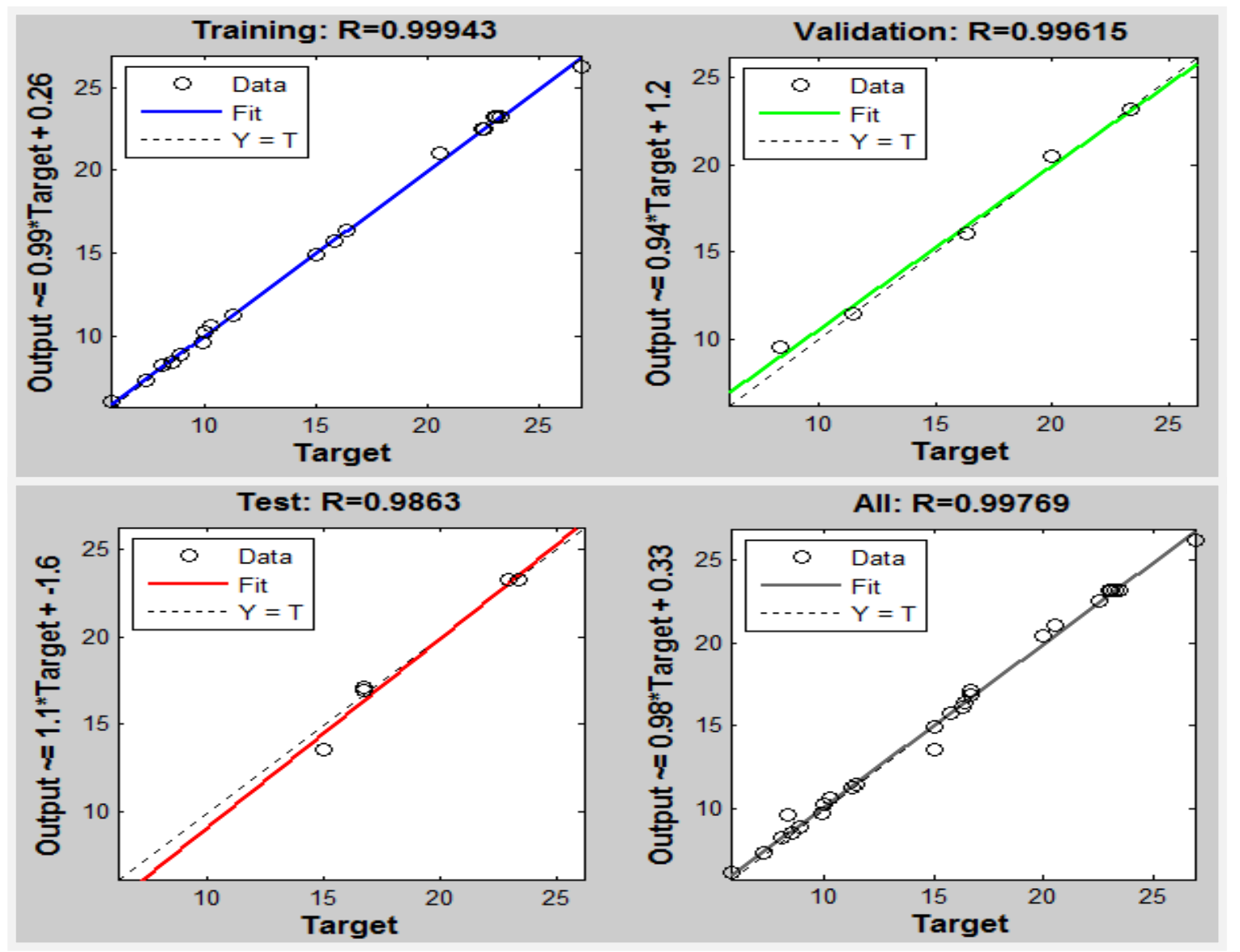

Fig.3 Correlation coefficients for mean pectin yield (ANN).

\section{Comparison of RSM and ANN Performance:}

To identify the best model that accurately predict the effect of extraction parameters on the yield, the prediction capabilities of the RSM and ANN models the computed values of all statistical indicators were compared. The result showed that both models indicate high of accurate of the result, since the higher $\mathrm{R}^{2}$ values were predicted in both cases. However, ANN gave a lower RMSE value when compared to the RSM model. Therefore, ANN was a better modeling tool due to its low RMSE and high extract yield. Owing to higher value of $\mathrm{R}^{2}$ and lower values of other statistical values of ANN compared to RSM, the accuracy of ANN model is better than that of the RSM model.

Table 4. Relative statistical indicators values of RSM and ANN model

\begin{tabular}{lll}
\hline Variables & RSM & ANN \\
\hline$R^{2}$ & 0.9678 & 0.9990 \\
RMSE & 0.627368 & 0.568154 \\
SEP & 0.007201 & 0.006576 \\
MAE & 0.521 & 0.352 \\
AAD & 0.547091 & 0.37780 \\
\hline
\end{tabular}




\section{Product Characterization}

The analyzed characteristics of the extracted pectins were indicated with their values and summarized in table 5 .

Table: 5. properties of extracted pectin with their values.

\begin{tabular}{llll}
\hline Parameters & Current Value (\%) & \multicolumn{2}{c}{ Previous value (\%) } \\
& & and References \\
& & 6.23 & Mohamed, (2016) \\
\hline Methoxyl content & 6.43 & 70.9 & 6.875 \\
Anhydrouronic acid & 68.25 & 0.4 & 60.95 \\
Acetyle content & 0.371 & 60.4 & 0.455 \\
EC & 63.13 & 599.74 & 55.01 \\
MW & 604.74 & & - \\
\hline
\end{tabular}

To represent the extent to which carboxyl groups in pectin molecules exist as the methyl ester, esterification capacity (EC) is an essential molecular index for pectin classification. Since result indicates, higher degree of esterification above50 percentage, it can be considered as high methoxyl (HM) pectin. Pectin's has high tendency to form gel rapidly at higher temperature and have a great effective action on the lipid profile, when degree of esterification is above 50 percent (Brouns et al., 2012; Dominiak et al., 2014). However, esterification capacity shows only the ratio between methanol-esterified carboxyl groups and free carboxyl groups, whereas the methoxyl rate represents to the amount of methoxyl groups in a sample (Fakayode and Abobi, 2018). So, the EC could not be judged separately, as it does not show the actual amount of methyl esterification, especially when the galacturonic acid amount is low. High methoxyl pectins (above 50\% EC) require a relatively a low $\mathrm{pH}$ for gel formation and large concentration of soluble solids, while pectins having methoxyl below 50\% EC, establish in flexible gels the using the movement of multivalent cations, which cross-hyperlink the galacturonic acid chains (Garna et al., 2004). In present study, the esterification capacity (EC) of the hydrated pectin was $63.13 \%$ similar to previous studies as shown in Table 5.

Another important characteristic in classifying the functional behavior of pectin is equivalent weight (EW) since, gelling tendency of individual pectin's are linked very closely with EW. The higher equivalent weight, has greater gel formation, while the lower equivalent weight, indicates larger partial degradation of the pectin which is non-profitable (Hardy, 1924) and thus the raise or diminish of the equivalent weight could be subjected to the content of free acid (Mohamed, 2016).The average equivalent weight of orange peel pectin in this study found to be $604.74 \mathrm{kDa}$ closest to data reported by Altaf et al. (2015), that the equivalent weigh of the pectin extracted form papaya fruits using $\mathrm{HCl}$ and Citric acids were 912.17 and 455.1 respectively and stated that, pectin produced at lower $\mathrm{pH}$ value, has higher equivalent weight, since lower $\mathrm{pH}$ can lead polymerization of pectin into an extended chain, and in turn decrease the amount of free acid..

The methoxyl content (MC) is an instrument tool used to control the setting time, the gel strength and to find the functional properties of 
pectin (Twinomuhwezi, Godswill and Kahunde,

2020). Kanmani, (2014), established that, depending on the origin of raw material used, method of extraction, in addition to the method used for determination of methoxyl content, the MC of pectin usually varies from $0.2-12 \%$. The result indicated that $6.23 \%$ of methoxyl content was achieved. Since the methoxyl content was below 12\%, this pectin has lower ester characteristic, which implies that it is desirable in terms of quality, and in addition due to it has above $50 \%$ DE.

As indication of Food Chemical Codex (FCC), Food and Agriculture Organization (FAO), and European Union (EU), pectin must contains at least $65 \%$ of galacturonic acid (Willats, Knox and Mikkelsen, 2006), since anhydrouronic acid amount is used to represent the gelling capabilities of given pectin. The higher value means, the produced pectin has a lower amount of protein. In present study, the result indicated that $68.25 \%$ of anhydrouronic acid was achieved. A minimum value of anhydrouronic acid (65\%) for commercial pectins has been specified by FAO (Twinomuhwezi, Godswill and Kahunde, 2020). This criterion has limited the potential sources of food and pharmaceutical pectins.

Acetyl value (AV); the gelling capacity of pectin diminished with the raise in the degree of acetylation Fakayode \& Abobi, (2018). The inhibition of gelormation will be created when acetyl formation is found in pectin. Other researcher shown that the gelling capacity of pectin diminished with raise in the degree of acetylation and samples holding 3.5\%-4.0\% acetyl brings weak gels while gelling capacity restored at levels around 2.4\% acetyl (Mohamed, 2016). Based on acetyl value and compared to previous study, the result indicates that orange peel pectin has good gelling capacity $(0.371 \%)$ table 5 .

\section{Conclusion}

The ultrasound-assisted extraction of pectin was optimized by the combination of both response surface methodology (RSM) and artificial neural network multi-layer back propagation (ANNMBP). The objectives of study were extraction of pectin from orange peel using ultrasound assisted extraction and response surface method and artificial neural network technique. The accuracy of the two models was studied to compare the performances of the two models to making decision for achievement of optimum process parameters during extraction of the pectin.

The following findings are absorbed from the effects of extraction parameters and technique used. The ultrasound assisted extraction and $\mathrm{pH}$ of citric acid solution applied for the extraction of pectin were found to be strongly influenced the yield. However, $\mathrm{pH}$ solution was highly significant compared to ultrasound power. As well as interaction between ultrasound and $\mathrm{pH}$ solution were found to be strongly influenced the extraction yield of pectin. The optimal conditions for extraction were irradiation time of $22.5 \mathrm{~min}, \mathrm{pH}$ of 1.5 , and ultrasound power of $155 \mathrm{~W}$ and liquid-solid ratio 22.5:1 mL/ g. Under these conditions, yield of pectin was $26.87 \%$ experimentally, while 26.74 and $26.93 \%$ of yield were predicted by RSM and ANN model respectively.

The extracted pectin of orange peel was categorized as high methoxyl pectin since it has $63.13 \%$ degree of esterification that is above $50 \%$ affirmed by FTIR detection.

The prediction of yield was investigated by using RSM and ANN model and found to be in good agreement with experimental data, however, the prediction of ANN model is found to be better than RSM. The results indicate that, ANN model is 


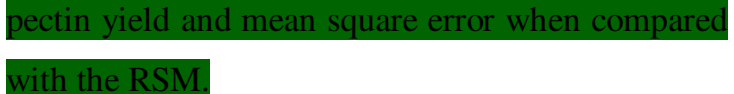

Ethics approval and consent to participate

Not applicable" in this section.

\section{Consent for publication}

The manuscript does not contain data from any individual person, therefore "Not applicable" in this section.

\section{Availability of data and materials}

The datasets used and/or analyzed during the current study are available from the corresponding author on reasonable request.

\section{Abbreviations}

EDESV11.1: Ease Design Expert software version 11.1 .0

FT-IR: Fourier transform infrared spectroscopy detection

UAE: Ultrasound assisted extraction

ANN: Artificial neural network

RSM; Response surface methodology

\section{Competing interests}

Regarding the publication of this paper, the author declare that there is no any Competing of interests

\section{Funding}

Tanks to my family members and School of Chemical Engineering, staffs for their financial support up to the end of this research, especially for data analysis

\section{Authors' contributions}

The author completed the research with the help of Chemical engineering and chemistry laboratory assistances for data analysis.

\section{Acknowledgement}

I like to acknowledge Jimma institute of Technology, School of Chemical Engineering, Addis Ababa University, Department of Chemistry and all lab technicians for their support us in different ways.

\section{References}

Altaf, U., Immanuel, G. and Iftikhar, F. (2015)

'Extraction and characterization of pectin derived from papaya (carica papaya linn.) Peel', International Journal of Science, Engineering and Technology, 3(4), pp. 1-5. doi: 10.2348/ijset07150970.

Berkani, F. et al. (2020) 'Response Surface Methodology Optimization of Microwave-Assisted Polysaccharide Extraction from Algerian Jujube ( Zizyphus lotus L .) Pulp and Peel'. Journal of Pharmaceutical Innovation.

Brouns, F. et al. (2012) 'Cholesterol-lowering properties of different pectin types in mildly hypercholesterolemic men and women', European Journal of Clinical Nutrition. Nature Publishing Group, 66(5), pp. 591-599. doi: 10.1038/ejen.2011.208.

Chan, S. Y. and Choo, W. S. (2013) 'Effect of extraction conditions on the yield and chemical properties of pectin from cocoa husks', Food Chemistry. Elsevier Ltd, 141(4), pp. 3752-3758. doi: 10.1016/j.foodchem.2013.06.097.

Cheok, C. Y. et al. (2012) 'Optimization of total phenolic content extracted from Garcinia mangostana Linn. hull using response surface methodology versus artificial neural network', 
Industrial Crops and Products. Elsevier B.V., 40(1), pp. 247-253. doi:

10.1016/j.indcrop.2012.03.019.

Dominiak, M. et al. (2014) 'Application of enzymes for efficient extraction, modification, and development of functional properties of lime pectin', Food Hydrocolloids. Elsevier Ltd, 40, pp. 273-282. doi: 10.1016/j.foodhyd.2014.03.009.

Dranca, F. (2019) 'Ultrasound-Assisted Extraction of Pectin from Malus', (231).

Fakayode, O. A. and Abobi, K. E. (2018)

'Optimization of oil and pectin extraction from orange (Citrus sinensis) peels: a response surface approach', Journal of Analytical Science and Technology. Journal of Analytical Science and Technology, 9(1). doi: 10.1186/s40543-018-01513.

Garna, H. et al. (2004) 'New method for a two-step hydrolysis and chromatographic analysis of pectin neutral sugar chains', Journal of Agricultural and Food Chemistry, 52(15), pp. 4652-4659. doi: 10.1021/jf049647j.

Ghoreishi, S. M., Hedayati, A. and Mousavi, S. O. (2016) 'Quercetin extraction from Rosa damascena Mill via supercritical CO2: Neural network and adaptive neuro fuzzy interface system modeling and response surface optimization', Journal of Supercritical Fluids. Elsevier B.V., 112, pp. 57-66. doi: 10.1016/j.supflu.2016.02.006.

Hamai, H. et al. (2020) 'Optimization of the extraction of orange peel pectin and evaluation of its antiproliferative activity towards HEp2 cancer cells', Euro-Mediterranean Journal for Environmental Integration. Springer International Publishing, 7, pp. 1-8. doi: 10.1007/s41207-02000179-7.
Hardy, F. (1924) 'The Extraction of Pectin from the Fruit Rind of the Lime (Citrus medica acida)', Biochemical Journal, 18(2), pp. 283-290. doi: 10.1042/bj0180283.

Hosseini, S. S. et al. (2019a) 'International Journal of Biological Macromolecules Optimization and characterization of pectin extracted from sour orange peel by ultrasound assisted method', International Journal of Biological Macromolecules. Elsevier B.V., 125, pp. 621-629. doi: 10.1016/j.ijbiomac.2018.12.096.

Hosseini, S. S. et al. (2019b) 'International Journal of Biological Macromolecules Optimization and characterization of pectin extracted from sour orange peel by ultrasound assisted method', International Journal of Biological Macromolecules. Elsevier B.V., 125, pp. 621-629. doi: 10.1016/j.ijbiomac.2018.12.096.

Hosseini, S. S., Khodaiyan, F. and Yarmand, M. S. (2016a) 'Aqueous extraction of pectin from sour orange peel and its preliminary physicochemical properties', International Journal of Biological Macromolecules. Elsevier B.V., 82, pp. 920-926. doi: 10.1016/j.ijbiomac.2015.11.007.

Hosseini, S. S., Khodaiyan, F. and Yarmand, M. S. (2016b) 'International Journal of Biological Macromolecules Aqueous extraction of pectin from sour orange peel and its preliminary physicochemical properties', International Journal of Biological Macromolecules. Elsevier B.V., 82, pp. 920-926. doi: 10.1016/j.ijbiomac.2015.11.007.

Hosseini, S. S., Khodaiyan, F. and Yarmand, M. S. (2016c) 'Optimization of microwave assisted extraction of pectin from sour orange peel and its physicochemical properties', Carbohydrate Polymers. Elsevier Ltd., 140, pp. 59-65. doi: 10.1016/j.carbpol.2015.12.051. 
Kanmani, P. (2014) 'Extraction and Analysis of Pectin from Citrus Peels: Augmenting the Yield from Citrus limon Using Statistical Experimental Design', Iranica Journal of energy and environment, 5(3), pp. 303-312. doi: 10.5829/idosi.ijee.2014.05.03.10.

Khayet, M., Cojocaru, C. and Essalhi, M. (2011) 'Artificial neural network modeling and response surface methodology of desalination by reverse osmosis', Journal of Membrane Science. Elsevier B.V., 368(1-2), pp. 202-214. doi: 10.1016/j.memsci.2010.11.030.

Kim, W. C. et al. (2004) 'Optimization of narirutin extraction during washing step of the pectin production from citrus peels', Journal of Food Engineering, 63(2), pp. 191-197. doi: 10.1016/j.jfoodeng.2003.07.001.

Kleijnen, J. P. C. (2008) 'Response surface methodology for constrained simulation optimization: An overview', Simulation Modelling Practice and Theory, 16(1), pp. 50-64. doi: 10.1016/j.simpat.2007.10.001.

Kliemann, E. et al. (2009) 'Optimisation of pectin acid extraction from passion fruit peel (Passiflora edulis flavicarpa) using response surface methodology', International Journal of Food Science and Technology, 44(3), pp. 476-483. doi: 10.1111/j.1365-2621.2008.01753.x.

Lin, C. B., Kai, N. Y. and Ali, A. (2018)

'Ultrasound assisted extraction of pectin from dragon fruit peels', Journal of Engineering Science and Technology, 13(Special Issue on the seventh eureca 2016), pp. 65-81.

Madadlou, A. et al. (2009) 'Response surface optimization of an artificial neural network for predicting the size of re-assembled casein micelles', Computers and Electronics in
Agriculture, 68(2), pp. 216-221. doi:

10.1016/j.compag.2009.06.005.

Marić, M. et al. (2018) 'An overview of the traditional and innovative approaches for pectin extraction from plant food wastes and by-products: Ultrasound-, microwaves-, and enzyme-assisted extraction', Trends in Food Science \& Technology. Elsevier Ltd. doi: 10.1016/j.tifs.2018.03.022.

Mohamed, H. (2016) 'Extraction and Characterization of Pectin from Grapefruit Peels', MOJ Food Processing \& Technology, 2(1), pp. 3138. doi: 10.15406/mojfpt.2016.02.00029.

Muthusamy, S. et al. (2019) 'Pectin extraction from Helianthus annuus (sunflower) heads using RSM and ANN modelling by a genetic algorithm approach', International Journal of Biological Macromolecules. Elsevier B.V, 124, pp. 750-758. doi: 10.1016/j.ijbiomac.2018.11.036.

Nazerian, M. et al. (2018) 'Comparison of response surface methodology (RSM) and artificial neural networks (ANN) towards efficient optimization of flexural properties of gypsum-bonded fiberboards', Cerne, 24(1), pp. 35-47. doi: $10.1590 / 01047760201824012484$.

Ng, H. S. et al. (2020) 'Recent advances on the sustainable approaches for conversion and reutilization of food wastes to valuable bioproducts', Bioresource Technology. Elsevier, 302(135), p. 122889. doi: 10.1016/j.biortech.2020.122889.

Prakash Maran, J. et al. (2014) 'Microwave assisted extraction of pectin from waste Citrullus lanatus fruit rinds', Carbohydrate Polymers. Elsevier Ltd., 101(1), pp. 786-791. doi: 10.1016/j.carbpol.2013.09.062.

Prakash Maran, J., Mekala, V. and Manikandan, S. 
(2013) 'Modeling and optimization of ultrasoundassisted extraction of polysaccharide from Cucurbita moschata', Carbohydrate Polymers. Elsevier Ltd., 92(2), pp. 2018-2026. doi: 10.1016/j.carbpol.2012.11.086.

Rahmani, Z. et al. (2020) 'Optimization of microwave-assisted extraction and structural characterization of pectin from sweet lemon peel', International Journal of Biological

Macromolecules. Elsevier B.V., 147(xxxx), pp. 1107-1115. doi: 10.1016/j.ijbiomac.2019.10.079.

Salleh, M. A. M. et al. (2011) 'Cationic and anionic dye adsorption by agricultural solid wastes: A comprehensive review', Desalination. Elsevier B.V., 280(1-3), pp. 1-13. doi: 10.1016/j.desal.2011.07.019.

Samavati, V. (2013) 'Polysaccharide extraction from Abelmoschus esculentus: Optimization by response surface methodology', Carbohydrate Polymers. Elsevier Ltd., 95(1), pp. 588-597. doi: 10.1016/j.carbpol.2013.02.041.

Sharma, K. et al. (2017) 'Converting citrus wastes into value-added products: Economic and environmently friendly approaches', Nutrition. Elsevier Inc., 34, pp. 29-46. doi: 10.1016/j.nut.2016.09.006.

Shivamathi, C. S. et al. (2019) 'Optimization of ultrasound assisted extraction of pectin from custard apple peel : Potential and new source', Carbohydrate Polymers. Elsevier, 225(August), p. 115240. doi: 10.1016/j.carbpol.2019.115240.

Tesli, N. et al. (2019) 'Chemical Engineering \& Processing : Process Intensi fi cation Defatted wheat germ as source of polyphenols Optimization of microwave- assisted extraction by RSM and ANN approach', 143(August). doi: 10.1016/j.cep.2019.107634.
Twinomuhwezi, H., Godswill, A. C. and Kahunde, D. (2020) 'Extraction and Characterization of Pectin from Orange (Citrus sinensis), Lemon (Citrus limon) and Tangerine (Citrus tangerina)', American Journal of Physical Sciences, 1(1(2)), pp. 17-30.

Wikiera, A. et al. (2016) 'Endo-xylanase and endocellulase-assisted extraction of pectin from apple pomace', Carbohydrate Polymers, 142, pp. 199205. doi: 10.1016/j.carbpol.2016.01.063.

Willats, W. G. T., Knox, J. P. and Mikkelsen, J. D. (2006) 'Pectin: New insights into an old polymer are starting to gel', Trends in Food Science and Technology, 17(3), pp. 97-104. doi: 10.1016/j.tifs.2005.10.008.

Ye, J., Zhang, P. and Hoffmann, E. (2014) 'Comparison of Response Surface Methodology and Artificial Neural Network in Optimization and Prediction of Acid Activation of Bauxsol for Phosphorus Comparison of Response Surface Methodology and Artificial Neural Network in Optimization and Prediction of', (November). doi: 10.1007/s11270-014-2225-1.

Zema, D. A. et al. (2018) 'Anaerobic digestion of orange peel in a semi-continuous pilot plant: An environmentally sound way of citrus waste management in agro-ecosystems', Science of the Total Environment. Elsevier B.V., 630, pp. 401408. doi: 10.1016/j.scitotenv.2018.02.168.

Zhang, X. et al. (2014) 'Extraction optimization of the polysaccharide from Adenophorae Radix by central composite design', International Journal of Biological Macromolecules. Elsevier B.V., 67, pp. 318-322. doi: 10.1016/j.ijbiomac.2014.03.039.

Zhao-Hui, X. et al. (2011) 'Optimization of Pectin Extraction from Citrus Peel by Response Surgace Methodology', Food Science, 18(18), pp. 128-132. 
Figures

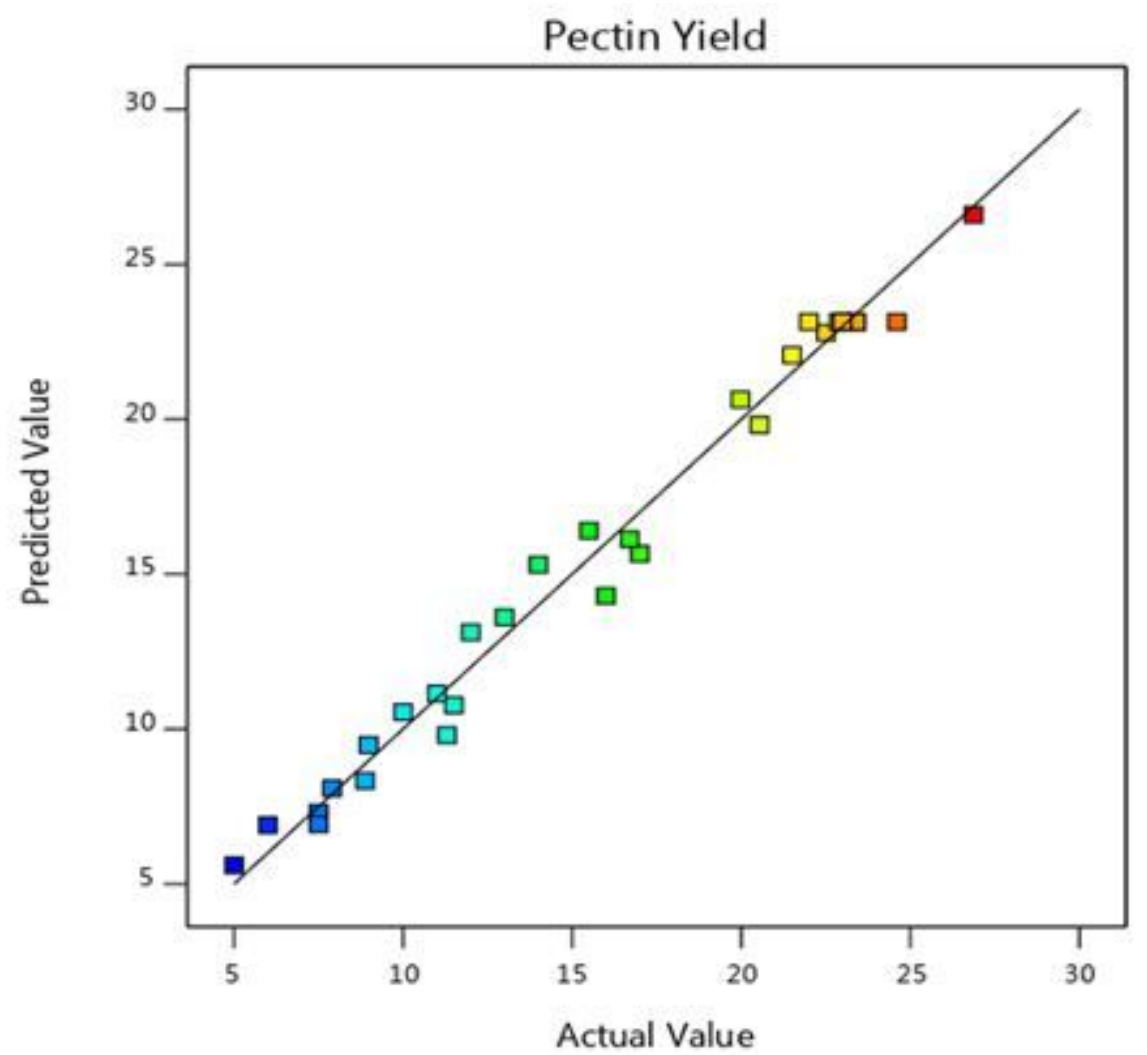

Figure 1

Experimental value versus RSM expected of pectin yield (\%).
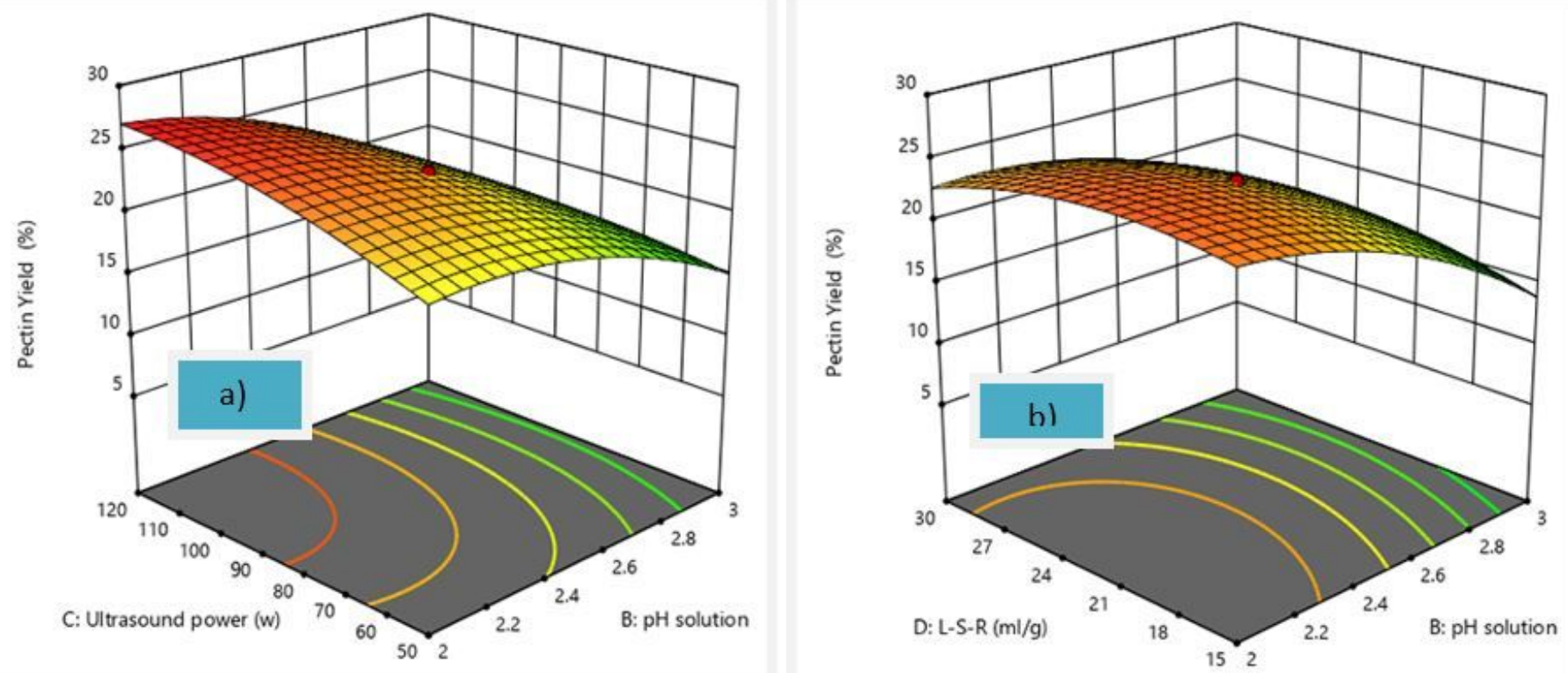

Figure 2 
Ultrasound versus $\mathrm{pH}(\mathrm{a})$ and Liquid-solid ratio versus $\mathrm{pH}$ on the yield of pectin (b)
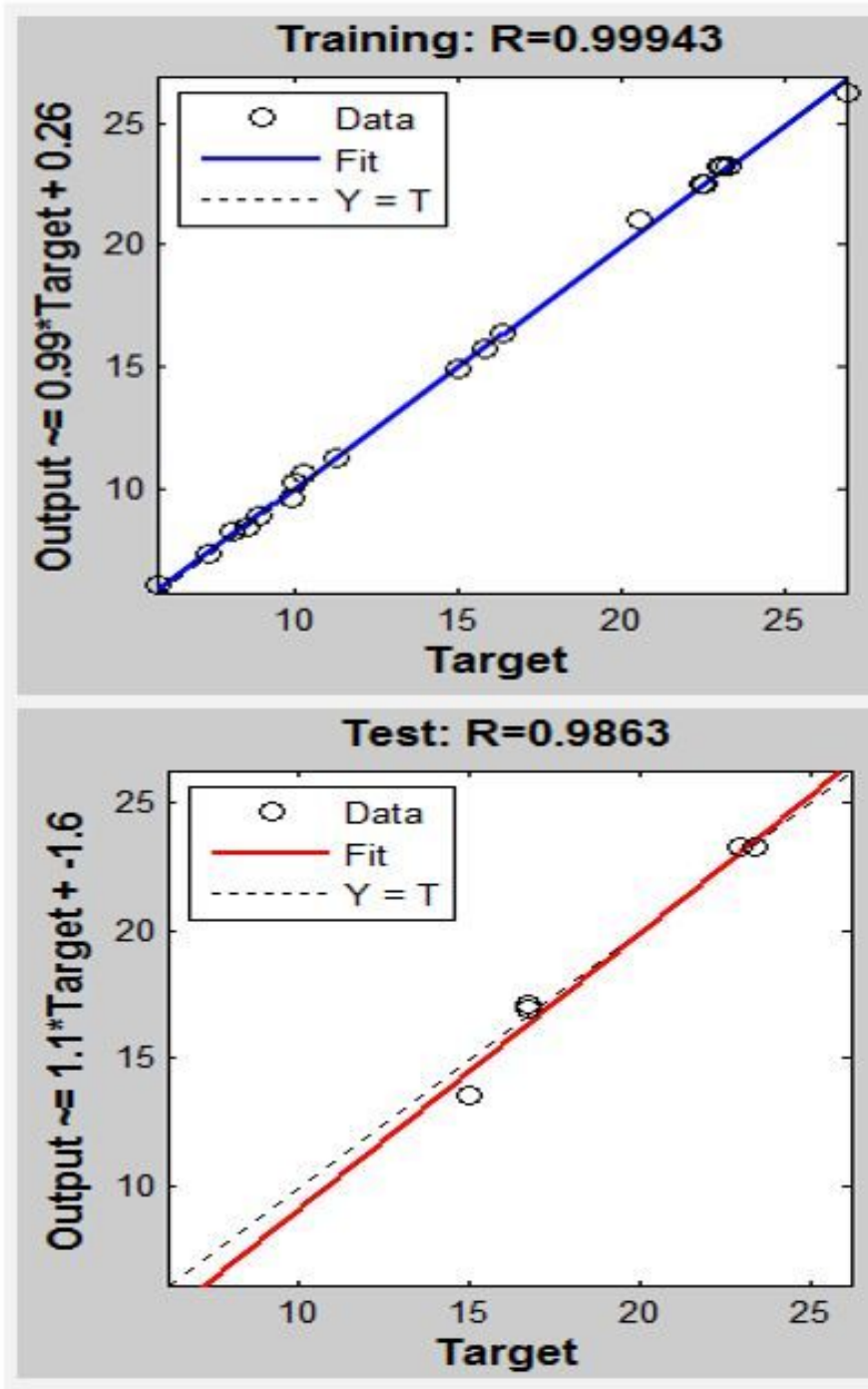
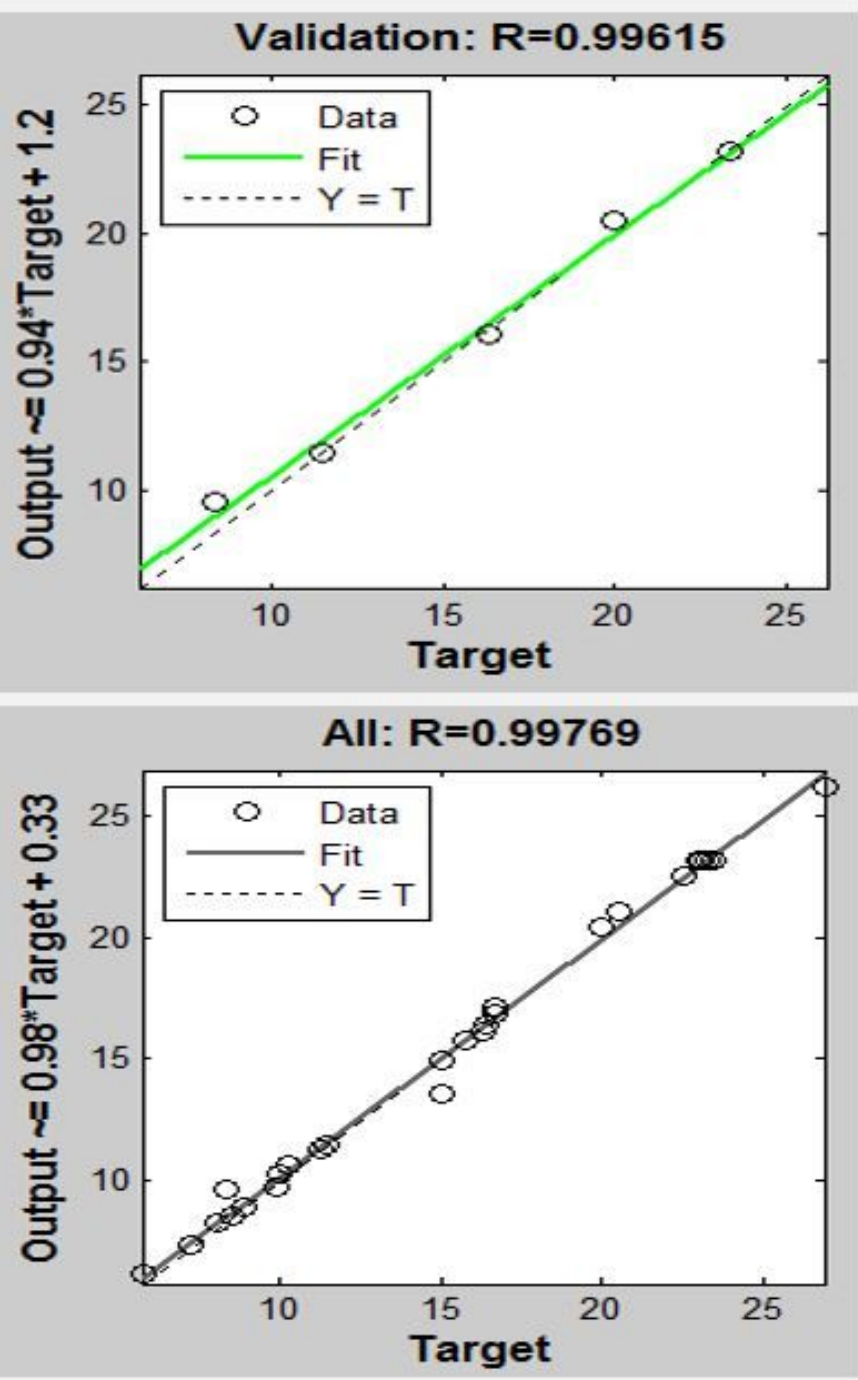

Figure 3

Correlation coefficients for mean pectin yield (ANN).

\section{Supplementary Files}

This is a list of supplementary files associated with this preprint. Click to download.

- Graphicalabstract.docx

- SUPMENTARYMATERIALS.docx 